\section{Progressive changes in diabetics and their management}

\begin{abstract}
The prevalence of diabetic retinopathy is increasing worldwide due to an increasing number, and prolonged survival, of diabetic patients. Many effective treatments for different types and stages of retinopathy exist. However, there is patchy delivery of care, inconsistent screening, and unresolved questions about several management questions. This article discusses the current state of knowledge about therapeutics in diabetic retinopathy, and highlights areas where further studies and evidence base is required.
\end{abstract}

Eye (2005) 19, 1115-1118. doi:10.1038/sj.eye.6701969

Keywords: diabetic retinopathy; macular oedema; vitrectomy; triamcinolone

\section{Introduction}

Retinal complications of diabetes were largely unknown prior to the advent of insulin treatment early in the last century. ${ }^{1}$ The dramatic increase in life expectancy brought about by that major medical advance brought with it unexpected late complications, including the diabetic retinopathy (DR). Despite the advent of many effective treatments, DR remains the commonest cause of blindness among younger patients in the developed world. ${ }^{2}$

The prevalence of diabetes is approximately $2 \%$ in the UK population, although it is vital to appreciate the wide variation in this figure among different ethnic groups. For example, the age-adjusted prevalence of diabetes among Asian groups can be as high as $16 \%{ }^{3}$ information which should be of interest to those planning ophthalmic services in different regions. In addition, prevalence of retinopathy in patients with DR varies widely, with one study of type II diabetes finding a prevalence
GW Aylward

84\% higher in Mexican-Americans than that in non-Hispanic whites. ${ }^{4}$

The problem is compounded by the increasing survival of patients with diabetic retinopathy, resulting in a higher incidence of severe, sight-threatening complications. The 5-year survival rate for patients with proliferative disease 50 years ago was 30\%, compared with figures today of $90 \%$ for patients with early-onset diabetes and $60 \%$ for patients with late-onset diabetes. ${ }^{5}$

An increase in the number of treatment modalities for progressive changes in DR, combined with the increased prevalence of the disease, have produced a significant resource problem for ophthalmologists, both now and in the future.

\section{Screening}

Almost all available treatments for DR are more effective when administered earlier rather than later, a fact that contributes to a solid case for an effective screening programme. It is therefore doubly tragic that in one study, over $50 \%$ of patients registered blind from DR had never been screened. ${ }^{6}$ One of the best definitions of screening is 'The identification, among apparently healthy individuals, of those who are sufficiently at risk of a specific disorder to justify a subsequent diagnostic test or procedure'. ${ }^{7}$ This paper also set out sound criteria for conditions that benefit from screening, all of which apply to DR. The NHS has finally recognised the benefits of a coordinated screening programme. Standard 10 of the National Service Framework (NSF) for diabetes requires that all young people and adults with diabetes will receive regular surveillance for the long-term complications of diabetes. ${ }^{8}$ This requires the development of a national scheme for a screening programme that enables annual monitoring for diabetic retinopathy.

Much attention has been focused on the most cost-effective method of screening. Manpower
Vitreoretinal Surgical Unit, Moorfields Eye Hospital, City Road, London, UK

Correspondence: GW Aylward, Vitreoretinal Surgical Unit, Moorfields Eye Hospital, City Road, London EC1V 2PD, UK Tel: + 442075662039 ; Fax: +442075662039. E-mail: Bill.Aylward@ moorfields.nhs.uk

Received: 28 April 2005 Accepted: 2 May 2005 
limitations, plus increasing use of information technology mean that the concept of screening photographs instead of patients is attractive. It has been tried with mixed success in various studies using nonmydriatic fundus camera. ${ }^{9}$ Problems occurred because of poor quality photographs but more recent studies have shown the method to be cost-effective when mydriatics are used. ${ }^{10,11}$ However, the capital cost of current machines is high, and their bulk and weight makes portability a problem. Nevertheless, photographic screening with centralised reading centres is rapidly becoming the most popular screening modality in the UK. ${ }^{12}$

\section{Evidence-based treatment}

Evidence for the effectiveness of current treatments for diabetic retinopathy is of high quality, due to several major, well-conducted, randomised studies over the last three decades. Modern management of progressive changes is based largely on the results of these trials.

The Diabetes Control and Complications Trial (DCCT) aimed to discover whether tight control could reduce the risk of late complications, specifically diabetic retinopathy and nephropathy. ${ }^{13}$ A total of 1441 patients with type I diabetes were randomised to either conventional or intensive treatment. Patients were followed up for an average of nearly 7 years. The study found a favourable reduction in the prevalence of significant retinopathy in the intensive treatment group (27 vs 76\%).

The United Kingdom prospective diabetic retinopathy study (UKPDS) recruited 4209 patients with newly diagnosed type II diabetes and randomised them into conventional and intensive treatment groups with an average follow up of 10 years. ${ }^{14}$ The study found that the intensive treatment group had a significant reduction in progression and severity of DR. For example, there was a $29 \%$ reduction in the need for laser photocoagulation, a $23 \%$ reduction in vitreous haemorrhage, and a $16 \%$ reduction in blind registration.

The purpose of the diabetic retinopathy study (DRS) was to discover whether laser photocoagulation could reduce blindness from proliferative diabetic retinopathy (PDR). ${ }^{15,16}$ One eye of each patient was randomised to photocoagulation, and the fellow eye was used as a control. Scatter laser or Xenon arc was used for photocoagulation. Severe visual loss (SVL) was defined as a visual acuity of 5/200 on two consecutive follow up visits. Overall, the rate of SVL was reduced by $50 \%$ in the treatment eyes. For eyes with high risk PDR, the 5-year risk of SVL was reduced from 50 to $20 \%$.
The early treatment DRS examined patients with nonproliferative DR and non-high-risk proliferative DR, with or without macular oedema. ${ }^{17,18}$ One eye of each patient was randomly assigned to early photocoagulation. The study found that focal photocoagulation reduced risk of moderate visual loss by $50 \%$ and increased the chance of a small improvement in visual acuity. It also found that scatter photocoagulation was not helpful in eyes with nonproliferative retinopathy except in eyes close to having high-risk characteristics.

The diabetic retinopathy vitrectomy study (DRVS) examined the benefit of vitrectomy for complications of PDR. ${ }^{19}$ Eyes with severe vitreous haemorrhage reducing visual acuity to 5/200 and a duration 1-6 months were assigned randomly to early vitrectomy or conventional management. The study found that the visual recovery was more likely in the treatment group (50\%) than in the conventional management group (12\%).

\section{Practical issues in delivery of treatment}

What is the end point for panretinal photocoagulation?

The DRS showed that the application of 1500 retinal burns with scatter treatment was effective in halving the rate of severe visual loss. ${ }^{15}$ However, almost all ophthalmologists aim to apply at least 2000 burns for a 'basic' PRP. It is widely assumed that applying further photocoagulation until new vessels regress, or become 'inactive' is beneficial, although there are few good studies to support this belief. Certainly there are many patients who have insufficient laser, often because of a combination of factors. Often partial vitreous haemorrhage reduces the area of retina, which can be effectively treated. Some patients, particular young patients with type I diabetes, find PRP painful, and this gets worse on subsequent occasions because pigmentation from laser scars results in greater heat absorption. As a result, there is a subgroup of patients who, although detected early, enter a downward spiral of progression of new vessels and development of complications. This spiral can often be interrupted by the use of the indirect laser, ${ }^{20}$ using either good local anaesthesia or even a short general anaesthetic in selected, bilateral cases. One of the major advantages of the indirect laser is the ability to indent and apply effective PRP to the peripheral retina, a region that is often missed out with standard contact lens delivery.

When deciding whether further PRP is required, the importance of the vitreous is paramount. If a complete PVD is present, there is no scaffold for new vessels to grow into, and no vitreoretinal interface for them to grow along. In this situation, the persistence of active new vessels may be tolerated, particularly since further PRP 
may lead to significant visual field defects, and subsequent problems meeting driving standards. In contradistinction, a fully attached vitreous and 'flat' active new vessels may lead to fibrovascular proliferation along the interface, leading ultimately to traction retinal detachment.

Recurrent vitreous haemorrhage may be due to 'active new vessels', and may therefore prompt the application of further PRP. However, there is a relatively common, but underrecognised syndrome where a posterior vitreous detachment is complete, except for a fibrous stalk to the site of previous new vessels, usually at the optic disk. The fibrous stalk inserts into a retinal vein, and dynamic vitreous traction related to eye movements is responsible for recurrent venous bleeding. This is not the result of 'active' new vessels and recurrent haemorrhages will continue despite more laser. Once recognised, the correct management for this syndrome is vitrectomy, with relief of traction.

\section{What is the best timing for vitrectomy?}

The DVS showed that vitrectomy was beneficial, and also that a significant proportion of treated patients still went onto severe visual loss. ${ }^{19}$ It is important to realise that the DVS was conducted nearly 20 years ago, and there have been many changes in vitrectomy surgery since then. In particular, no endolaser was used in the study, yet now it is a routine part of vitrectomy treatment for DR. In fact the results of vitrectomy and endolaser for diabetic vitreous haemorrhage in the absence of retinal detachment are extremely good, and this is a treatment that should be considered at a much earlier stage. ${ }^{21}$ It is now common to advise surgery if there has been no clearing at 3 months after onset.

Recurrent vitreous haemorrhage may be due to 'active new vessels', and may therefore prompt the application of further PRP. However, there is a relatively common syndrome where a posterior vitreous detachment is complete, except for a fibrous stalk to the site of previous new vessels, usually at the optic disk. The fibrous stalk inserts into a retinal vein, and dynamic vitreous traction related to eye movements is responsible for recurrent venous bleeding. This is not the result of 'active' new vessels and recurrent haemorrhages will continue despite more laser. Once recognised, the correct management for this syndrome is vitrectomy, with relief of traction.

\section{How should we treat macular oedema?}

Macular oedema is a very common cause of visual loss in diabetics. Clinical significant macular oedema within one disc diameter of the fovea is present in $9 \%$ of diabetics. ${ }^{22}$
It is also more common in patients with more severe DR and can, for example, limit visual improvement in eyes with successfully managed proliferative disease. ${ }^{23}$ The ETDRS showed a clear benefit of focal laser photocoagulation, although the study did not distinguish between the clinical entities of focal and diffuse leakage. It is likely that much of the treatment effect was due to resolution of leakage in the former group. Interest in surgical treatment for diffuse oedema was stimulated by the publication of a series of patients with a 'taut, posterior hyaloid'. In all, 10 patients with this syndrome were treated by vitrectomy and peeling of the posterior hyaloid, and $80 \%$ experienced significant visual improvement. ${ }^{24}$ Subsequent uncontrolled series appeared to support this observation. Since then, vitrectomy has been attempted in eyes without evidence of traction, and indeed in even in eyes without attached gel. Indeed, there is some rationale for removing the vitreous in patients with diabetic macular oedema, even in the absence of obvious traction. The vitreous may act as a reservoir for cytokines, and its removal is know to increase oxygen tension at the retinal surface. Simple vitrectomy and peeling has been enhanced by the additional step of removing the internal limiting membrane (ILM peeling). However, although a recent large prospective study showed reduced oedema, only a minority of patients experienced any visual improvement. ${ }^{25}$ A recent randomised trial of vitrectomy for macular oedema in the absence of visible traction (but with attached gel) has shown no benefit in the treatment group compared with controls treated with further grid laser. $^{26}$

The use of intravitreal triamcinolone has become very popular over the last 2 years for a number of conditions, including diffuse diabetic macular oedema. Uncontrolled studies have indicated a benefit in terms of reduction in macular oedema, sometimes associated with visual improvement. However, the effect does not appear to be sustained, and both macular thickening and visual acuity return to a pretreatment state after 4-6 months. ${ }^{27}$ In addition, high rates of post-treatment raised intraocular pressure have been reported, and endophthalmitis remains a risk.

\section{Summary}

Despite the good evidence base for treatment in DR, the management of progressive changes remains a challenge, with many practical problems remaining unanswered.

The assessment of the state of the vitreous is of underestimated importance when planning further PRP. The role of vitrectomy in diabetic macula oedema currently remains unclear, and further randomised studies will be required to refine its indications. 
Although increasingly popular, intravitreal triamcinolone appears to have anatomical effects, but limited long-term benefit on vision.

\section{References}

1 Banting FG, Best CH, Collip JB, Campbell WR, Fletcher AA. Pancreatic extracts in the treatment of diabetes mellitus: preliminary report. 1922. Can Med Assoc J 1991; 145: 1281-1286.

2 National Institutes of Health and National Institute of Diabetes and Digestive and Kidney Diseases. Diabetes in America. 2nd edn. US Government Printing Office: Bethesda, MD, USA, 1995.

3 Simmons D, Williams DR, Powell MJ. Prevalence of diabetes in different regional and religious south Asian communities in Coventry. Diabet Med 1992; 9: 428-431.

4 Harris MI, Klein R, Cowie CC, Rowland M, Byrd-Holt DD. Is the risk of diabetic retinopathy greater in non-Hispanic blacks and Mexican Americans than in non-Hispanic whites with type 2 diabetes? A US population study. Diabetes Care 1998; 21: 1230-1235.

5 Pelzek C, Lim JI. Diabetic macular oedema: review and update. Ophthalmol Clin N Am 2002; 15: 555-563.

6 Clark JB, Grey RH, Lim KK, Burns-Cox CJ. Loss of vision before ophthalmic referral in blind and partially sighted diabetics in Bristol. Br J Ophthalmol 1994; 78 : 741-744.

7 Wald N, Cuckle H. Reporting the assessment of screening and diagnostic tests. Br J Obstet Gynaecol 1989; 96: 389-396.

8 Department of Health. National service framework for diabetes. 2001.

9 Barrie T, MacCuish AC. Assessment of non-mydriatic fundus photography in detection of diabetic retinopathy. $\mathrm{Br}$ Med J 1986; 293: 1304.

10 Lairson DR, Pugh JA, Kapadia AS, Lorimor RJ, Jacobson J, Velez R. Cost-effectiveness of alternative methods for diabetic retinopathy screening. Diabetes Care 1992; 15: 1369-1377.

11 Higgs ER, Harney BA, Kelleher A, Reckless JP. Detection of diabetic retinopathy in the community using a nonmydriatic camera. Diabetic Med 1991; 8: 551-555.

12 Murgatroyd H, Ellingford A, Cox A, Binnie M, Ellis JD, MacEwen CJ et al. Effect of mydriasis and different field strategies on digital image screening of diabetic eye disease. Br J Ophthalmol 2004; 88: 920-924.

13 Diabetes Control and Complications Trial Research Group. Progression of retinopathy with intensive versus conventional treatment in the Diabetes Control and Complications Trial. Ophthalmology 1995; 102: 647-661.

14 UK Prospective Diabetes Study Group. Tight blood pressure control and risk of macrovascular and microvascular complications in type 2 diabetes: UKPDS 38. BMJ 1998; 317: 703-713.

15 The Diabetic Retinopathy Study Research Group. Preliminary report on effects of photocoagulation therapy. Am J Ophthalmol 1976; 81: 383-396.

16 The Diabetic Retinopathy Study Research Group. Four risk factors for severe visual loss in diabetic retinopathy. The third report from the Diabetic Retinopathy Study. Arch Ophthalmol 1979; 97: 654-655.

17 Early Treatment Diabetic Retinopathy Study Research Group. Treatment techniques and clinical guidelines for photocoagulation of diabetic macular edema. Early Treatment Diabetic Retinopathy Study report number 2. Ophthalmology 1987; 94: 761-774.

18 Early Treatment Diabetic Retinopathy Study Research Group. Techniques for scatter and local photocoagulation treatment of diabetic retinopathy. Early Treatment Diabetic Retinopathy Study report no. 3. Int Ophthalmol Clin 1987; 27: 254-264.

19 Diabetic Retinopathy Vitrectomy Study Research Group. Early vitrectomy for severe proliferative diabetic retinopathy in eyes with useful vision. Clinical application of results of a randomized trial. Diabetic Retinopathy Vitrectomy Study report 4. Ophthalmology 1988; 95: 1321-1334.

20 Gurelik G, Coney JM, Zakov ZN. Binocular indirect panretinal laser photocoagulation for the treatment of proliferative diabetic retinopathy. Ophthalmic Surg Lasers Imaging 2004; 35: 94-102.

21 Smiddy WE, Flynn HW. Vitrectomy in the management of diabetic retinopathy. Surv Ophthalmol 1999; 43: 491-507.

22 Klein R, Klein BE, Moss SE, Cruikshanks KJ. The Wisconsin Epidemiologic study of diabetic retinopathy: IV, diabetic macular oedema. Ophthalmology 1984; 91: 1464-1474.

23 Hikichi T, Fujio N, Akiba J, Azuma Y, Takahashi M, Yoshida A. Association between the short-term natural history of diabetic macular oedema and the vitreomacular relationship. Ophthalmol 1997; 104: 473-478.

24 Lewis H, Abrams GW, Blumenkranz MS, Campo RV. Vitrectomy for diabetic macular oedema associated with posterior hyaloidal traction. Ophthalmology 1992; 99: 753-759.

25 Dillinger P, Mester U. Vitrectomy with removal of the internal limiting membrane in chronic diabetic macular oedema. Graefe's Arch Clin Exp Ophthalmol 2004; 242: 630-637.

26 Thomas D, Bunce C, Moorman C, Laidlaw DA. A randomised controlled feasibility trial of vitrectomy versus laser for diabetic macular oedema. Br J Ophthalmol 2005; 89: 81-86.

27 Massin P, Audren F, Haouchine B, Erginay A, Bergmann JF, Benosman $\mathrm{R}$ et al. Intravitreal triamcinolone acetonide for DMO: preliminary results of a prospective controlled trial. Ophthalmology 2004; 111: 218-224. 